\title{
Acquisition of Information About Innovative Practices in Outpatient Mental Health Clinics
}

\author{
Karissa M. Fenwick ${ }^{1}$. Lawrence A. Palinkas ${ }^{2} \cdot$ Michael S. Hurlburt $^{2} \cdot$ Rebecca D. Lengnick-Hall $^{3} \cdot$ Sarah M. Horwitz $^{4}$. \\ Kimberly E. Hoagwood ${ }^{4}$
}

Published online: 10 March 2020

○) Springer Science+Business Media, LLC, part of Springer Nature 2020

\begin{abstract}
This study uses qualitative interviews with leaders of 34 mental health clinics in the context of a statewide rollout of clinical and business innovations to explore how clinics first learn about innovations and which external sources of information they access. Clinic leaders reported accessing information about innovations mainly from government agencies, professional associations, peer organizations, and research literature. Leaders mentioned an average of two external sources of information. There was evidence of variation in how leaders accessed information and how information about innovations was communicated within clinics. Findings have implications for improving dissemination of information about innovations in mental health systems.
\end{abstract}

Keywords Evidence-based practice · Quality improvement · Implementation

Researchers have identified a range of effective clinical interventions for child and adolescent mental, emotional, and behavioral disorders, such as cognitive-behavioral therapies and parent management therapies (Chorpita et al. 2011; Kadzin and Weisz 2003; Kendall et al. 2008; Silverman and Hinshaw 2008; Sofronoff and Farbotko 2002). They have also developed effective business and quality improvement practices to optimize mental health service delivery, including standardized assessments and measurement feedback systems (Bickman et al. 2016; Gleacher et al. 2016; Hoagwood et al. 2014). However, low rates of innovation adoption and poor or partial implementation indicate that simply developing effective innovations is not enough to change

Karissa M. Fenwick

Karissa.Fenwick@va.gov

1 Center for the Study of Healthcare Innovation, Implementation and Policy (CSHIIP), VA Greater Los Angeles Healthcare System, 11301 Wilshire Blvd (206), Los Angeles, USA

2 Suzanne Dworak-Peck School of Social Work, University of Southern California, Los Angeles, CA, USA

3 Brown School, Washington University in St. Louis, St. Louis, USA

4 Department of Child and Adolescent Psychiatry, New York University, New York, NY, USA practice in community-based mental health organizations (Balas and Boren 2000; Green 2008). Further research is needed to identify factors and processes that support implementation of innovations and in turn improve clinical outcomes for children, adolescents and their families (Chor et al. 2015).

Adoption is the first step in the implementation process during which organizational staff decide whether to proceed with full or partial implementation of an innovation (Wisdom et al. 2014). In their Exploration, Preparation, Implementation, Sustainment framework Aarons et al. (2011) note that the Exploration and Adoption stage begins when a potential adopter seeks out, acquires, or is otherwise exposed to an innovation. A theoretical framework of adoption by Wisdom et al. (2014) divides adoption into two phases: (1) pre-adoption, during which organizational staff gain awareness of an innovation and access relevant information with which to make an adoption decision, and (2) established adoption, during which organizational leaders weigh the risks and benefits of adoption and decide whether to commit to the innovation. This paper focuses on the pre-adoption phase, during which organizational staff gain awareness of an innovation and access relevant information with which to make an adoption decision (Mendel et al. 2008; Wisdom et al. 2014). The activities and tasks in the pre-adoption phase set the tone for successful adoption and 
implementation, yet there are relatively few empirical studies directly examining them (Bradley et al. 2004; Chor et al. 2015; Fixsen et al. 2005; Panzano and Roth 2006; Powell et al. 2019; Proctor et al. 2011).

Exposure to credible sources of information about innovations in the pre-adoption phase introduces organizational staff to innovations, assists them in identifying innovations to address specific needs, helps them weigh the adoption decision, and encourages them to direct adequate resources to the adoption effort (Aarons et al. 2011; Bradley et al. 2004; Glisson and Schoenwald 2005; Mendel et al. 2008; Panzano and Roth 2006; Wisdom et al. 2014). In contrast, lack of access to and familiarity with innovations hinders adoption (Bradley et al. 2004; Feldstein and Glasgow 2008; Solomons and Spross 2011). Beyond adoption, acquisition and use of information about innovations is associated with implementation and sustainment (Palinkas et al. 2017). Given that procurement of information about an innovation is necessary for organizational adoption and implementation to proceed, it is important to examine how organizational leaders learn about innovations (Palinkas et al. 2015b).

Leaders may learn about innovations from both impersonal communication channels and social networks. Impersonal channels, including emails and mass media, spread innovations to large audiences and play an important role during the early phase of adoption (Greenhalgh et al. 2004; Rogers 2003; Valente et al. 2007). However, social networks may have greater influence on the overall success of adoption (Greenhalgh et al. 2004; Mendel et al. 2008; Wisdom et al. 2014). Social networks facilitate adoption by creating access to information and support, and by offering opportunities for collaboration around adoption (Palinkas et al. 2011, 2017; Valente et al. 2007; Valente and Davis 1999). Organizations may adopt innovations in response to external sources in their networks, such as other community-based organizations or state and county colleagues (Horwitz et al. 2014; Palinkas et al. 2015b). Additional potential outside sources of information include university researchers, program developers, consultants, conferences, or professional associations, although some literature suggests that these sources may be relied upon less often (Horwitz et al. 2014).

In addition to identifying the external information sources that are most relevant to innovation adoption, it is also necessary to examine the internal organizational factors that may influence how information is accessed. Individual characteristics may determine how organizational leaders search for and explore information about innovations. For example, some leaders may take a passive approach to receiving information, while others may proactively seek information about new practices (Greenhalgh et al. 2004; Rogers 2003). Organizations may also vary in terms of how much they encourage internal staff to share information they learn about innovations, and whether they adopt innovations due to interest or recommendations from staff members (Horwitz et al. 2014).

\section{The Current Study}

In order to initiate adoption, organizational staff must first gain awareness of and acquire knowledge about an innovation. However, little is known about how organizations first learn about innovations, which external sources of information about innovations they rely on, or whether differences in acquisition of information may be associated with differences in adoption behavior. The current study uses qualitative interviews with community mental health agency/clinic leaders to provide real world examples of the external sources and processes that influence information acquisition. The objectives of this study are: (1) identify commonly accessed external sources of information on innovative practices in community mental health clinics; and (2) explore differences in acquisition of information between clinics with higher levels of innovation training adoption versus lower levels of innovation training adoption during a statewide initiative.

\section{Methods}

\section{Data and Sample}

Study data comes from a parent study examining innovation adoption in the context of a New York State initiative to scale up clinical and business innovations in child and adolescent mental health services (Hoagwood et al. 2014). The Community Technical Assistance Center (CTAC) was founded in 2011 and funded by the New York State Office of Mental Health $(\mathrm{OMH})$ to provide training, consultation, and education around business and clinical skills. At the time of the present study, CTAC provided assistance to all statelicensed clinics serving children, even if children comprised only a small proportion of the case mix. The scope of the CTAC has since been expanded to serve all outpatient mental health clinics licensed by the state of New York (www. ctacny.org).

In 2011-2014, when data for the current study were collected, the CTAC offered training in three modalities-webinars, in-person seminars, and learning collaboratives-that represent escalating levels of intensity and clinic commitment. Hour-long webinars represent the least intensive training modality; all-day in-person seminars represent mid-level intensity; and 6-18 month learning collaboratives are the most intensive. The CTAC has since broadened its offerings and modified its focus, but at the time of data collection in 
the present study the CTAC offered 33 trainings. Eighteen of these trainings targeted evidence-based clinical practices, twelve trainings targeted improvement of business practices, and three hybrid trainings targeted improvement of both clinical and business practices. Clinical (or EBP) trainings included topics such as cognitive-behavior therapy, strengthening families, and motivational interviewing. Business (or QI) trainings included topics such as collaborative documentation, quality assurance and risk management, and financial self-assessment. A list of trainings is provided in the Appendix, and more detail about them may be found elsewhere (Chor et al. 2014).

Sending staff to be trained in an innovation represents an early clinic adoption behavior (Nadeem et al. 2018; Olin et al. 2015). Chor et al. (2014) examined the naturalistic participation in CTAC trainings of all 346 clinics licensed to treat children, adolescents, and their families in New York State between 2011 and 2013. They categorized clinics into non-adopters (did not access any trainings); low adopters (accessed webinars only); medium adopters (accessed at least one in-person seminar but no learning collaboratives); high adopters (accessed one learning collaborative); and super adopters (accessed at least two learning collaboratives). Chor et al. (2014) found that these training adoption levels were significantly associated with the number of trainings a clinic accessed overall (i.e. higher-adopting clinics accessed more trainings), offering preliminary evidence that they represent meaningful clinic-level engagement in innovation training activities. A mean of $6.87 \pm 5.89$ providers per clinic participated in any business trainings and $7.09 \pm 5.35$ clinicians per clinic participated in any clinical trainings (Chor et al. 2014).

The present study uses data from 34 clinics that were randomly selected from within Chor et al.'s (2014) training adoption categories to represent a $10 \%$ stratified sample of the 346 clinics in the larger study. Although randomized sampling is not typically considered an ideal form of purposive sampling for qualitative methods, this approach was used to ensure that clinics in the less common adoption categories (i.e. super adopters) were represented and that major variations in perspectives related to adoption were captured (National Cancer Institute 2018; Palinkas et al. 2015a). Table 1 contains clinic characteristics.

\section{Interviews}

Qualitative interview data were collected in 2013-2014 from 65 clinic leaders. Leaders were identified from websites and

Table 1 Clinic descriptive statistics by level of adoption

\begin{tabular}{|c|c|c|c|c|c|c|}
\hline \multirow[t]{2}{*}{ Characteristic } & \multicolumn{6}{|c|}{ Percentage of clinics by level of adoption } \\
\hline & Overall & Super $(n=3)$ & High $(n=10)$ & Medium $(n=5)$ & Low $(n=5)$ & None $(n=11)$ \\
\hline Clinic numbers & & $1-3$ & $4-13$ & $14-18$ & $19-23$ & $24-34$ \\
\hline \multicolumn{7}{|l|}{ Region } \\
\hline Central & 9 & 0 & 30 & 0 & 0 & 0 \\
\hline Hudson Valley & 15 & 0 & 0 & 40 & 40 & 9 \\
\hline Long Island & 3 & 0 & 0 & 0 & 20 & 0 \\
\hline NYC & 62 & 67 & 50 & 60 & 40 & 82 \\
\hline Western & 12 & 33 & 20 & 0 & 0 & 9 \\
\hline \multicolumn{7}{|l|}{ Annual expenses } \\
\hline$<\$ 1$ million & 13 & 0 & 20 & 0 & 0 & 20 \\
\hline$\$ 1-\$ 5$ million & 53 & 100 & 60 & 25 & 80 & 30 \\
\hline$\$ 5-\$ 10$ million & 16 & 0 & 0 & 50 & 20 & 20 \\
\hline$>\$ 10$ million & 19 & 0 & 20 & 25 & 0 & 30 \\
\hline \multicolumn{7}{|c|}{ Gain or loss per service unit } \\
\hline$<-\$ 50$ & 13 & 0 & 10 & 0 & 0 & 30 \\
\hline$-\$ 50-\$ 0$ & 50 & 67 & 60 & 50 & 60 & 30 \\
\hline$>\$ 0$ & 38 & 33 & 30 & 50 & 40 & 40 \\
\hline \multicolumn{7}{|c|}{ Percentage of youth clients } \\
\hline$<25$ & 50 & 0 & 60 & 25 & 60 & 60 \\
\hline $25-50$ & 31 & 67 & 30 & 25 & 40 & 20 \\
\hline $50-75$ & 6 & 33 & 0 & 25 & 0 & 0 \\
\hline $75-100$ & 13 & 0 & 10 & 25 & 0 & 20 \\
\hline
\end{tabular}

Financial and client population information for two clinics is not available. Percentages are based on the number of clinics with available data on that characteristic 
CTAC databases and asked if they would be willing to be interviewed about their clinic's adoption of innovations. Within most clinics, two interviews were conducted: one with an upper level administrator (e.g. CEO or Vice President) and one with a middle level manager (e.g. Program Director). Within three clinics, only one interview was conducted due to simpler organizational structures, and within one clinic a third interview was conducted with an additional key decision-maker.

Fourteen percent of upper level administrators were CEOs, $6 \%$ were COOs, $26 \%$ were Vice Presidents, $11 \%$ were Executive Directors, 9\% were Associate Executive Directors, and 34\% had other directorial titles (e.g. Agency Director, Director of Behavioral Health Services). Middle level managers had titles of Program Director or Clinic Director. Clinic leaders' demographic information was not collected. Informed consent was obtained from all participants, and study procedures were approved by the Institutional Review Boards of University of Southern California and New York University. Clinic leaders received a \$25 gift card for their participation.

Interviews with clinic leaders were completed via telephone and lasted approximately 30-50 min. Interviews were semi-structured and conducted as part of a larger study examining clinic leader experiences with learning about innovations, adoption decision-making, adoption of CTAC innovations, and barriers/facilitators of innovation adoption.

Relevant to the present study, participants answered questions about their initial exposure and access to clinical and business innovations, including how they first learn about innovations, who provides information about innovation adoption, and what type of information is provided. Interview questions were selected from a conceptual model of use of research evidence proposed by Palinkas et al. (2017). Lead interview questions included: "How does your agency typically first hear about an innovation?" "Who generally informs your agency about participating in innovations?" "What information is generally provided about an innovation the first time your agency hears about it?" Participants were prompted to clarify or expand upon their answers using probes such as "What relation is this person/are these persons to you and your agency?" and "Are there people within your agency who talk to you about innovations?" Other prompts used depended on the needs of the interview; for example, "Can you think of any other sources or are those the main ones?" or "Does the information come by email?".

Although the larger study examined adoption of CTAC innovations, questions in the present study pertained to innovations generally, rather than CTAC innovations specifically. At the beginning of each interview, the interviewer emphasized that participants should consider both EBPs and QI initiatives as innovations: "Innovations can be evidence-based practices for specific psychiatric disorders, and they can also be quality improvement initiatives, which are activities to improve the structures, processes, and outcomes of care of your clinic. From here on, when I use the word "innovation", I am referring to both EBPs and QI." Subsequent interview questions did not differentiate between EBP and QI innovations, instead using "innovations" as an umbrella term for both types of practices.

\section{Data Analysis}

Interviews were transcribed by four researchers who were part of the larger, original study. Data was coded in Dedoose Version 8.0.35 using a deductive-inductive hybrid thematic content analysis method of "Coding Consensus, Co-occurrence, and Comparison" (Willms et al. 1990). The first author coded all transcripts, and a graduate level researcher coded $50 \%$ of transcripts selected at random. Clinic characteristics, including clinic levels of training adoption, were masked during coding to minimize bias.

First, open coding was used to identify broad themes and patterns, and then axial coding was used to explore these themes more deeply (Strauss and Corbin 1998). The co-coders created detailed memos to describe codes and document decision-making (Charmaz 2014; Strauss and Corbin 1998). Discrepancies in coding were discussed until consensus was reached. Interrater reliability, calculated from 10 randomly selected transcripts, was $92 \%$ (range $89-95 \%$ ), indicating good reliability (Padgett 2012; Viera and Garrett 2005).

Given that leaders at different levels of a single organization may have access to different external information sources and observe different organizational processes for accessing information, interviews conducted in the same organization were treated as independent. Themes and patterns of code applications for upper-level and middle-level leaders were compared using a matrix of codes, but did not indicate systematic differences between the two leader groups.

After coding was complete, a template organizing style was used to compare codes from interviews with clinic leaders in super/high-adopting clinics with those from low/ non-adopting clinics (Crabtree and Miller 1999). The first author developed a matrix of themes and compared the content and organization of the matrix to identify themes that were common to both groups of clinics as well as themes that were specific to only one group (Crabtree and Miller 1999). Medium-adopting clinics were then compared with both super/high and low/non-adopting clinics. 
Table 2 Percentage of clinic leaders endorsing external sources of information about innovations

\begin{tabular}{|c|c|c|c|c|c|}
\hline \multirow[t]{2}{*}{ Source } & \multirow[t]{2}{*}{ Example } & \multicolumn{4}{|c|}{ Clinic level of adoption } \\
\hline & & Overall & Super/high & Medium & Low/none \\
\hline Office of mental health & Center for practice innovations & 72 & 68 & 56 & 81 \\
\hline Peer organization/network & The Coalition for Behavioral Health in New York City & 34 & 24 & 45 & 39 \\
\hline Other government & Office of Alcoholism and Substance Abuse Services & 26 & 24 & 56 & 19 \\
\hline Professional association & National Council for Behavioral Health & 25 & 20 & 45 & 23 \\
\hline Literature & Journals, databases & 29 & 40 & 45 & 16 \\
\hline University & New York University & 9 & 4 & 22 & 10 \\
\hline Email & Email blasts, listserves & 54 & 48 & 56 & 58 \\
\hline Meetings & Extraorganizational, in-person meetings & 20 & 24 & 33 & 13 \\
\hline Mean number of sources & & 2.0 & 1.8 & 2.7 & 1.9 \\
\hline
\end{tabular}

\section{Results}

Table 2 indicates the proportion of leaders who mentioned a source of information or theme in response to interview prompts. Qualitative findings related to sources and themes are presented below. Efforts are made to present quotes from a wide variety of participants. To improve readability, some quotes were edited to remove unnecessary utterances and redundant wording.

Differences in findings between super/high and low/nonadopting agencies are discussed where applicable. On some themes, medium-adopting clinics appeared most similar to super/high-adopting clinics, on other themes they were most similar to low/non-adopting clinics, and on others they were mixed. Several caveats should be kept in mind while interpreting these findings. First, 'adoption' in this study was defined as level of participation in $\mathrm{OMH}$-sponsored trainings, and did not consider other types of adoption behaviors or participation in non-OMH trainings. Second, given that this is a qualitative study, no inferential statistical tests were performed and findings should be interpreted as qualitative assessments by the investigators.

\section{External Information Sources}

The New York State Office of Mental Health (OMH) was the most frequently identified source for information about innovations ( $72 \%$ of leaders). In some cases, leaders identified specific $\mathrm{OMH}$-funded resources such as the Center for Practice Innovations (CPI) and the CTAC. Three leaders explicitly stated that the most common way their organization first learned about an innovation was through $\mathrm{OMH}$.

“...they $[\mathrm{OMH}]$ have been really helpful in trying to help the mental health agencies in the State to be more aware of the evidence-based practices out there, and quality initiatives as well. So OMH is certainly a very important source." [Agency Director, 21].
The majority of leaders at every training adoption level-including those in clinics that did not access the CTAC trainings offered by $\mathrm{OMH}$-reported that they received or accessed information about innovations through OMH. However, two leaders in low/non-adopting agencies reported that they did not view OMH as an important source of information. As one stated, "When it's mandated we get things from OMH. But we don't consider OMH the leading innovator." [Vice President, 33].

Finally, four leaders in super/high-adopting clinics and one leader in a medium adopting clinic described collaborative relationships with $\mathrm{OMH}$, as opposed to simply receiving $\mathrm{OMH}$ communication indirectly such as through a list serve mailing. These leaders described mutually beneficial partnerships with $\mathrm{OMH}$ and active roles in shaping OMH initiatives related to innovations, as reported by one leader:

"Well, certainly, [OMH] also discusses with us what it is they're looking at in terms of initiatives. And where I' $m$ at, this is something that's doable because we have a collaborative relationship with them." [Vice President, 9].

It was unclear from the interviews whether clinics with existing collaborative relationships with $\mathrm{OMH}$ were more likely to participate in trainings, or whether collaborations between $\mathrm{OMH}$ and clinics were strengthened during the course of training participation.

Beyond $\mathrm{OMH}$, clinic leaders reported accessing a wide range of government sources of information about innovations (26\% of leaders). These included federal (e.g. Substance Abuse and Mental Health Services Administration; National Institute of Mental Health), state (e.g. Office of Alcoholism and Substance Abuse Services; Administration for Children's Services; Department of Education) and local (e.g. New York City Department of Health and Mental Health) sources. These sources were often linked to the clinic's funding, as explained by one leader: 
"We are very active in terms of fundraising. And so we also scan the funding opportunities. And very often as part of that, there will be potential evidence based practices identified. So that's also another vehicle by which we may hear about something." [Program Director, 16].

Non-government sources of information included peer networks, professional organizations, research literature, and universities. In the peer organization/network category (34\% of leaders), the most frequently mentioned source was The Coalition for Behavioral Health, which represents approximately 150 community-based behavioral health agencies in NYC and the surrounding area. One leader stated:

"The Coalition provides support. They are the ones that disseminate the information of what's going on and the new trends that are emerging in mental health." [Vice President, 2].

Professional associations, such as the American Psychological Association and the National Council for Behavioral Health, were another important source of information (25\% of leaders). One leader stated, "We view that [National Council for Behavioral Health] conference as an essential tool to expose us to what's happening not only throughout the company in terms of other providers, but at the federal level in terms of policy." [CEO, 22].

Leaders also accessed information about innovations from research literature or databases (29\% of leaders). Leaders in super/high-adopting clinics were more likely to indicate taking an active approach to seeking out and looking up information. Eight leaders in super/highadopting agencies (approximately one-third) used language that suggested that they actively searched for information about innovations. As one such leader reported, "We've been pretty proactive, and so we have done some literature reviews...so some combination of proactive searching and seeing opportunities that come up from public funders." [Program Director, 8].

In contrast, leaders in medium and low/non-adopting clinics were less likely to describe proactive searches, with only two leaders using language suggesting they actively searched out information about innovations rather than passively receiving it. Two leaders in low/nonadopting agencies expressed feeling overwhelmed with the task of processing current incoming information and stated that they did not have the capacity for additional searches: "I don't have the time." [Program Director, 24]. These findings were not explained by known organizational characteristics (i.e. clinics were not outliers in terms of annual expenses or gain/loss per service unit).
Universities were the least frequently mentioned source of information (9\% of leaders). Leaders who identified this source generally described receiving the information through university mailing lists, though two leaders mentioned having deeper affiliations with local universities, such as participating on projects related to innovations.

\section{Modality}

Clinic leaders reported that emails were the most common modality through which they received information about innovations from outside sources. They typically received these emails via mailing lists or impersonal email 'blasts'. One leader described the numerous mailing lists through which they accessed information.

"It's obviously being on, everyone's on every list serve it seems. So I get 150 emails a day and half of those are from, whether it's advocacy groups or associations that are encouraging things, whether it's from the federal government talking about a promising practice. So I'd say we get them from a lot of different places, as well as from the leadership in our own county who are saying, you know, we're interested in this model or that model." [Program Director, 4].

Less frequently, leaders reported hearing about innovations through extra-organizational meetings, such as conferences or committees. Of those leaders who mentioned hearing about innovations in meetings, $83 \%$ of those in super/high-adopting clinics and 50\% of those in mediumand low/non-adopting clinics specifically stated that they learned about innovations during conversations with peers and colleagues.

“There's a Mental Health Director's meeting. And then there's the school-based mental health support team meetings. Often conversations about... practice innovations come up at those meetings." [Agency Director, 8].

\section{Intra-organizational Communication}

Clinic leaders described internal organizational processes for sharing knowledge about innovations once it entered the organization. In some cases, leaders described bottom-up communication, in which staff clinicians distributed information about innovations up the organizational hierarchy. Thirty-six percent of leaders in super/high-adopting organizations described this kind of communication, compared to $16 \%$ of leaders in low/non-adopting organizations and $22 \%$ of leaders in medium-adopting organizations.

"Our clinicians will also, either through their licensing bodies or just through colleagues, they'll bring poten- 
tial training opportunities. Our psychiatrists will, from time to time, bring training opportunities. So really, any of the clinic staff could potentially run across different things that they feel would useful in part of their practice and bring those either to the treatment team as a whole or to me specifically in an effort to see if that's something we might be able to support." [Vice President, 10].

Other clinic leaders described top-down approaches to disseminating information in which they or other leaders distributed information throughout the organization. Thirty-two percent of these leaders were from low/non-adopting clinics, compared to $22 \%$ from medium-adopting and $8 \%$ from super/ high-adopting clinics.

"Our health system actually tells us about new innovations that they're working on. And that's the primary way that's passed down to us... Usually, the Assistant Vice President will call me and will call other clinic directors to let me know what we're working on. They'll have a presentation for our clinic." [Clinic Director, 31].

Leaders in four clinics reported their organization had training institutes or departments that managed the dissemination of innovations within the agency. Three of these clinics [28, $29,14]$ were relatively large (annual expenses greater than $\$ 8$ million) compared to the rest of the sample. Three of the clinics were non-adopters of CTAC trainings [28, 29, 31], and the fourth was a medium adopter [14]. It is unclear from the interview data whether the presence of internal training resources was a factor in clinic decisions to participate in CTAC trainings.

\section{Information Content}

Regarding information content, approximately half of the leaders interviewed described the types of information about innovations they most frequently access or receive. They reported that this information typically consists of a 'basic overview' about an innovation, or 'broad strokes' information about trainings, initiatives, or mandates. About a quarter of leaders described the types of information about innovations that they personally wanted or sought out. They looked for information about the innovation's evidence base and relevance to their client population. They also wanted information to help them evaluate whether or not the innovation is a good fit for their clinic, including details about feasibility, cost, and what the implementation process may entail. For example, one leader said:

“...I generally am interested in reading about programs or sites that have implemented. And the details of implementation and how it's being applied kind of in the real world, and what the benefits and challenges of that are. That's kind of my specific interest when I kind of hear about an innovation or a best practice." [Agency Director, 12].

\section{Discussion}

This qualitative study examined mental health clinic leaders' descriptions of how their organizations first learn about clinical and business innovations and which types of external sources of information they access. Using training participation data from a statewide innovation rollout, it compared higher- versus lower- adopting clinics in terms of their information acquisition.

Clinic leaders endorsed accessing information about innovations from a variety of external sources, including the New York State Office of Mental Health (OMH), other government agencies, professional associations, peer organizations, research literature, and universities. Similar to other studies, $\mathrm{OMH}$ was the most frequently mentioned source, and universities were mentioned least (Horwitz et al. 2014).

There were some differences in how clinics accessed information. Although preliminary, our results suggested that leaders in higher-adopting clinics were more likely to report accessing information as a result of active searching, corroborating research indicating that information scanning is associated with innovation adoption (Knudsen and Roman 2004). In addition, leaders in higher-adopting clinics described obtaining information during in-person conversations with peers and colleagues at meetings and conferences more frequently than leaders in low-adopting clinics. These findings are in line with previous empirical studies demonstrating that interpersonal contacts and partnerships with external organizations are positively associated with innovation adoption (Palinkas et al. 2011; Valente 1996).

There was also evidence of differences in how clinics shared information about innovations within their organization. Leaders in higher-adopting clinics were more likely to describe both top-down and bottom-up internal processes for communicating information about innovations, in congruence with research noting that two-way, mutual information exchange supports adoption (Rogers 2003). Other clinics, particularly lower adopters, focused on topdown methods of disseminating information. Several of these clinics had their own internal training resources, introducing the possibility that some low-adopting clinics may have less need to access state sponsored trainings. However, more research is needed to empirically examine these findings. 


\section{Practical Implications}

Findings have practical implications for improving dissemination of information about innovations in public mental health services. As previously mentioned, the New York State OMH was the most frequently accessed source of external information about innovations, even among non-adopting clinics that did not participate in its recent large-scale, low cost innovation rollout. Further, leaders reported accessing only two different external sources on average. These findings offer preliminary evidence to suggest that disseminating information about innovations through oversight agencies may offer the greatest return on investment in terms of reaching the largest number of clinics. Study results also suggest that oversight agencies and technical assistance centers aiming to increase adoption should work to develop collaborative relationships with clinic leaders and support them in developing new networks and partnerships. However, the configuration of each service system will dictate which oversight agency is most salient (i.e. state, county, or city), and further research is needed to determine if these findings generalize to other service systems. Therefore, innovation developers should continue to distribute information about their interventions and products through provider coalitions and at national, state, and local professional associations.

Few leaders described accessing university sources of information about innovations, suggesting opportunities for researchers to consider pathways for disseminating information to community-based mental health clinics. Researchers can disseminate their work via newsletters, mailing lists, conferences, and meetings of peer coalitions and professional associations for clinics that serve their target population (Fernández-Peña et al. 2008). Researchers should also develop plans to build partnerships with and disseminate their work directly to relevant clinic leaders and service providers (Mendel et al. 2008). Similar to recommendations for disseminating research evidence to policy makers, researchers should develop materials that are concise, highlight practical impacts, and include information about innovation cost and implementation requirements where possible (Purtle et al. 2019). Additional work examining strategies for improving uptake of research among stakeholders in state mental health systems is currently underway (www.ideas4kidsmentalhealth.org).

Taken together with other research, study results suggest several recommendations for strengthening mental health organizations' capacity to access information about innovations. Leaders may be trained in how to effectively search for, evaluate, and process information about innovations. They can also be encouraged to engage in networking opportunities at coalition meetings, administrative meetings, and conferences in order to increase their exposure to conversations about innovations, in line with other research suggesting that social interactions are key for accessing discussions about research (Palinkas et al. 2017).

To increase intra-organizational communication about innovations, leaders should encourage staff to communicate information about innovations across hierarchical boundaries in addition to waiting for information or mandates related to innovations to trickle down from top administrators. Leaders and supervisors can also encourage staff to share information about innovations during clinical supervision, treatment team meetings, or staff meetings, although the time available to do this may be limited depending on the organization's current needs. Internal trainings should include dedicated time for open communication about ideas and innovations to facilitate knowledge transfer. Leaders may also signal that ideas about innovations are valued by regularly sharing research evidence, supporting staff efforts to learn more about innovations, and rewarding staff who disseminate information about innovations (Aarons et al. 2014,2016). These recommendations align with research suggesting that increasing dialogue about innovations and opening boundaries around the exchange of ideas can help organizations apply new knowledge about evidence-based practices (Aarons et al. 2014, 2017; Austin and Claassen 2008; Maynard 2010). They are also in line with studies indicating that active leadership is important for improving the organizational context of mental health clinics (Aarons and Sommerfeld 2012; Corrigan et al. 2001).

\section{Theoretical Implications}

Most empirical studies focus on implementation after the adoption decision is already made, with fewer delving into the processes that define the pre-adoption and adoption phases (Wisdom et al. 2014; Chor et al. 2015). This study offers examples of factors relevant to pre-adoption from a real world service context. Study findings contribute to conceptual frameworks of adoption and implementation of innovations in human service organizations, such as Wisdom et al.'s (2014) framework of adoption and Aarons et al.'s (2011) Exploration, Preparation, Implementation, and Sustainment (EPIS) framework. They offer empirical evidence of the most commonly accessed sources of information about innovations and preliminary information about factors related to information access. In addition, they illustrate how factors in the internal organizational context (i.e. clinic leaders) and external organizational context (i.e. external sources of information) interact during early adoption, in line with recent work indicating the importance exploring connections between the internal 
and external contexts for implementation science (Moullin et al. 2019).

\section{Limitations and Future Directions}

There are several limitations to this study. First, it is important to note that the numbers presented in tables and throughout the results section represent the proportion of leaders who mentioned a source or theme in their interview. Given that interviews did not include prompts related to every source (e.g. OMH, government) or theme (e.g. active searching, bottom-up communication), we should not conclude that a lack of mention indicates a true absence of the source or theme. Further, the reliance on retrospective accounts of clinic leaders introduces potential for social desirability bias, and restricting the sample to a single service system limits generalizability of findings to other states and contexts.

Other limitations related to the measurement of clinic training adoption should be considered when interpreting this study's results. Clinic training participation represents only one aspect of early adoption behavior, and our measure did not incorporate participation in non-OMH trainings. Further, the training adoption categories used in this study do not take into account the number of providers who attended each training.

In addition, the interview questions did not distinguish between EBP and QI innovations, preventing analysis of differences in sources of and access to information. Further, the lack of available demographic information about clinic leaders limits analysis of differences between leaders in higher- versus lower-adopting clinics, and the focus on clinic leaders excludes perspectives from other important stakeholders such as frontline service providers. Finally, the cross-sectional design of this study means that the directionality of the association between how a clinic accesses and uses external information and its level of training adoption cannot be established.

The limitations of this study suggest several areas for future investigation, such as longitudinal designs, replication in other states and service systems, inclusion of other stakeholder groups, and multi-indicator measures for adoption. Future studies are also needed to examine several gaps in this study's findings. Quantitative surveys can build on this study's results by asking clinic leaders to indicate whether or not they access a particular source of information, how important/useful the source is, and how often they access it. Future studies should also examine how information is used in making adoption decisions, whether different sources provide different types of information, whether there are differences in access to and acquisition of information about clinical practices versus business practices, and whether accessing information from particular sources improves adoption. Insight into these questions can further support strategies to increase dissemination and adoption of innovations.

Negative case analysis may offer a deeper understanding of study results. Approximately one quarter of leaders did not name the state $\mathrm{OMH}$ as a source of information, and several stated that they did not perceive the $\mathrm{OMH}$ as an important source. Collecting further information about such cases may provide insights into how state or local oversight agencies can improve their outreach and increase clinic buy-in. In addition, future studies should focus on leaders who report being overwhelmed with incoming information in order to develop strategies to help them manage and assimilate information about innovations. Finally, application of social network theory and analysis can be used to build on this study's results by examining how social networks influence access to information that facilitates selection and adoption of innovations (Palinkas et al. 2011; Valente et al. 2007).

\section{Conclusion}

Mental health service systems are constantly changing and new clinical interventions, quality improvement initiatives, and business approaches are continuously emerging (Hoagwood et al. 2014). To facilitate implementation of these innovations and close the research-practice gap, it is necessary to understand how clinics first learn about innovations for potential adoption. Despite its limitations, the results of this study offer preliminary understanding of the sources mental health organizations rely on for information about innovations. Findings also suggest opportunities for the development of implementation strategies to improve acquisition and sharing of information.

Acknowledgements Dr. Fenwick was supported by the VA Office of Academic Affiliations through the Advanced Fellowship in Health Services Research.

\section{Compliance with Ethical Standards}

Conflicts of interest The authors declare that they have no conflict of interest.

Ethical Approval All procedures performed in studies involving human participants were in accordance with the ethical standards of the institutional and/or national research committee and with the 1964 Helsinki declaration and its later amendments or comparable ethical standards.

\section{Appendix}

See Table 3. 
Table 3 List of CTAC Trainings from September 2011 to August 2013 Adapted from Chor et al. (2014)

\begin{tabular}{|c|c|c|c|}
\hline Type & Title & Intensity & Duration \\
\hline \multirow{18}{*}{$\begin{array}{l}\text { Clinical evidence- } \\
\text { informed } \\
\text { practices (18 } \\
\text { trainings) }\end{array}$} & Working with Children Suffering from Trauma-Trauma Assessment & Webinar & $1 \mathrm{~h}$ \\
\hline & Motivational Interviewing in Children's Services & Webinar & $1 \mathrm{~h}$ \\
\hline & Working with Children Suffering from Trauma-Trauma Treatment & Webinar & $1 \mathrm{~h}$ \\
\hline & Motivational Interviewing in Children’s Services, Part II & Webinar & $1 \mathrm{~h}$ \\
\hline & Autism Spectrum Disorders and Mental Health Outpatient Settings & Webinar & $1 \mathrm{~h}$ \\
\hline & Disaster Trauma in Outpatient Settings & Webinar & $1 \mathrm{~h}$ \\
\hline & Introduction to Cognitive Behavior Therapy (CBT) & Webinar & $1 \mathrm{~h}$ \\
\hline & Secondary Trauma and Compassion Fatigue & Webinar & $1 \mathrm{~h}$ \\
\hline & Family Focused Engagement in Child Mental Health Services & Webinar & $1 \mathrm{~h}$ \\
\hline & Parent Partnership & Webinar & $1 \mathrm{~h}$ \\
\hline & $\begin{array}{l}\text { CPT Coding Changes, in Partnership with the Coalition of Behavioral Health Agen- } \\
\text { cies }\end{array}$ & Webinar & $1 \mathrm{~h}$ \\
\hline & Child Development and the Brain: Promoting Resilience and Joy & Webinar & $1 \mathrm{~h}$ \\
\hline & Peers in Clinic: Improving Quality and Outcomes & Webinar & $1 \mathrm{~h}$ \\
\hline & Suicide Prevention: Recognize the Signs_-Take Actions to Save a Life & Webinar & $1 \mathrm{~h}$ \\
\hline & 4Rs and 2Ss (Group Model) Open Training [Strengthening families] & In-person & 1 day \\
\hline & $\begin{array}{l}\text { 4Rs and 2Ss (Group Model)—Rules, Roles and Responsibilities, Respectful Commu- } \\
\text { nication, Relationships, Stress, and Social Support [Strengthening families] }\end{array}$ & Learning collaborative & 12 months \\
\hline & $\begin{array}{l}\text { 4Rs and 2Ss (Individual Model) - Rules, Roles and Responsibilities, Respectful Com- } \\
\text { munication, Relationships, Stress, and Social Support [Strengthening families] }\end{array}$ & Learning collaborative & 6 months \\
\hline & Practitioner Education and Decision Support (PEDS) & Learning collaborative & 12 months \\
\hline \multirow{12}{*}{$\begin{array}{l}\text { Business/quality } \\
\text { improvement (12 } \\
\text { trainings) }\end{array}$} & Basic Tools to Get on the Road to Financial Planning & Webinar & $1 \mathrm{~h}$ \\
\hline & Financial Modeling Tools: Setting Benchmarks for Fiscal Viability & Webinar & $1 \mathrm{~h}$ \\
\hline & Integrating Services Delivery with your Financial Model: Understanding the Impact & Webinar & $1 \mathrm{~h}$ \\
\hline & $\begin{array}{l}\text { Managing your Workload: A Therapist Self-Management Tool for Productivity } \\
\text { Demands }\end{array}$ & Webinar & $1 \mathrm{~h}$ \\
\hline & $\begin{array}{l}\text { Uncovering the Elements: Quality Assurance, Corporate Compliance, and Risk } \\
\text { Management }\end{array}$ & Webinar & $1 \mathrm{~h}$ \\
\hline & Staff Performance Reporting and Monitoring: Coaching for Success & Webinar & $1 \mathrm{~h}$ \\
\hline & Business Webinar: Open Access & Webinar & $1 \mathrm{~h}$ \\
\hline & Business Webinar: Collaborative Documentation & Webinar & $1 \mathrm{~h}$ \\
\hline & Business Webinar: Centralized Scheduling & Webinar & $1 \mathrm{~h}$ \\
\hline & Successfully Meeting the Challenges of a Changing Behavioral Health System & In-person & 1 day \\
\hline & Business Efficiencies and Effectiveness Project (BEEP) & Learning collaborative & 18 months \\
\hline & Business Effectiveness Assessment Module (BEAM) & Learning collaborative & 6 months \\
\hline \multirow[t]{3}{*}{ Hybrid (3 trainings) } & Outcome Measurement: Clinical Support Tools & Webinar & $1 \mathrm{~h}$ \\
\hline & Outcome Measurement: Clinical Support Tools, Part II & Webinar & $1 \mathrm{~h}$ \\
\hline & Training Intervention for the Engagement of Families (TIES) & In-person & 1 day \\
\hline
\end{tabular}

\section{References}

Aarons, G. A., Ehrhart, M. G., Farahnak, L. R., \& Sklar, M. (2014). Aligning leadership across systems and organizations to develop a strategic climate for evidence-based practice implementation. Annual Review of Public Health, 35, 255-274. https://doi. org/10.1146/annurev-publhealth-032013-182447.

Aarons, G. A., Ehrhart, M. G., Moullin, J. C., Torres, E. M., \& Green, A. E. (2017). Testing the leadership and organizational change for implementation (LOCI) intervention in substance abuse treatment:
A cluster randomized trial study protocol. Implementation Science, 12, 29-39. https://doi.org/10.1186/s13012-017-0562-3.

Aarons, G. A., Green, A. E., Trott, E., Willging, C. E., Torres, E. M., Ehrhart, M. G., et al. (2016). The roles of system and organizational leadership in system-wide evidence-based intervention sustainment: A mixed-method study. Administration and Policy in Mental Health and Mental Health Services Research, 43(6), 991-1008. https://doi.org/10.1007/s10488-016-0751-4.

Aarons, G. A., Hurlburt, M., \& Horwitz, S. M. (2011). Advancing a conceptual model of evidence-based practice implementation in public service sectors. Administration and Policy in Mental 
Health and Mental Health Services Research, 38, 4-23. https ://doi.org/10.1007/s10488-010-0327-7.

Aarons, G. A., \& Sommerfeld, D. H. (2012). Leadership, innovation climate, and attitudes toward evidence-based practice during a statewide implementation. Journal of the American Academy of Child \& Adolescent Psychiatry, 51(4), 423-431. https://doi. org/10.1016/j.jaac.2012.01.018.

Austin, M. J., \& Claassen, J. (2008). Implementing evidence-based practice in human service organizations: Preliminary lessons from the frontlines. Journal of Evidence-Based Social Work, 5(1-2), 271-293. https://doi.org/10.1300/j394v05n01_10.

Balas, E. A., \& Boren, S. A. (2000). Managing clinical knowledge for health care improvement. In Bemmel J., \& McCray, A. T. (Eds.), Yearbook of medical informatics 2000: Patient-centered systems (65-70). Stuttgart, Germany: Schattauer. https://doi. org/10.1055/s-0038-1637943.

Bickman, L., Lyon, A. R., \& Wolpert, M. (2016). Achieving precision mental health through effective assessment, monitoring, and feedback processes: Introduction to the special issue. Administration and Policy in Mental Health and Mental Health Services Research, 43(3), 271-276. https://doi.org/10.1007/s1048 8-016-0718-5.

Bradley, E. H., Webster, T. R., Baker, D., Schlesinger, M., Inouye, S. K., Barth, M. C., ... Koren, M. J. (2004). Translating research into practice: Speeding the adoption of innovative health care programs. Commonwealth Fund Issue Briefs, 724, 1-13.

Charmaz, K. (2014). Constructing grounded theory: A practical guide through qualitative analysis (2nd ed.). Thousand Oaks, CA: Sage.

Chor, K. H. B., Olin, S. C. S., Weaver, J., Cleek, A. F., McKay, M. M., Hoagwood, K. E., et al. (2014). Adoption of clinical and business trainings by child mental health clinics in New York State. Psychiatric Services, 65(12), 1439-1444. https://doi.org/10.1176/ appi.ps.201300535.

Chor, K. H. B., Wisdom, J. P., Olin, S. C. S., Hoagwood, K. E., \& Horwitz, S. M. (2015). Measures for predictors of innovation adoption. Administration and Policy in Mental Health and Mental Health Services Research, 42(5), 545-573. https://doi. org/10.1007/s10488-014-0551-7.

Chorpita, B. F., Daleiden, E. L., Ebesutani, C., Young, J., Becker, K. D., Nakamura, B. J., ... Starace, N. (2011). Evidence-based treatments for children and adolescents: An updated review of indicators of efficacy and effectiveness. Clinical Psychology Science and Practice, 18(2), 154-172. https://doi.org/10.111 1/j.1468-2850.2011.01247.x

Corrigan, P. W., Steiner, L., McCracken, S. G., Blaser, B., \& Barr, M. (2001). Strategies for disseminating evidence-based practices to staff who treat people with serious mental illness. Psychiatric Services, 52(12), 1598-1606. https://doi.org/10.1176/appi. ps.52.12.1598.

Crabtree, B. F., \& Miller, W. L. (Eds.). (1999). Doing qualitative research. Thousand Oaks, CA: Sage.

Feldstein, A. C., \& Glasgow, R. E. (2008). A practical, robust, implementation and sustainability model (PRISM) for integrating research findings into practice. The Joint Commission Journal on Quality and Patient Safety, 34(4), 228-243. https://doi. org/10.1016/s1553-7250(08)34030-6.

Fernández-Peña, J. R., Moore, L., Goldstein, E., DeCarlo, P., Grinstead, O., Hunt, C., ... Wilson, H. (2008). Making sure research is used: Community-generated recommendations for disseminating research. Progress in Community Health Partnerships: Research, Education, and Action, 2(2), 171-176. https://doi.org/10.1353/ cpr.0.0013

Fixsen, D. L., Naoom, S. F., Blase, K. A., Friedman, R. M., \& Wallace, F. (2005). Implementation research: A synthesis of the literature. Tampa, FL: University of South Florida, Louis de la Parte Florida
Mental Health Institute, The National Implementation Research Network.

Gleacher, A. A., Olin, S. S., Nadeem, E., Pollock, M., Ringle, V., Bickman, L., ... Hoagwood, K. (2016). Implementing a measurement feedback system in community mental health clinics: A case study of multilevel barriers and facilitators. Administration and Policy in Mental Health and Mental Health Services Research, 43(3), 426-440.https://doi.org/10.1007/s10488-015-0642-0

Glisson, C., \& Schoenwald, S. K. (2005). The ARC organizational and community intervention strategy for implementing evidencebased children's mental health treatments. Mental Health Services Research, 7(4), 243-259. https://doi.org/10.1007/s1102 0-005-7456-1.

Green, L. W. (2008). Making research relevant: If it is an evidencebased practice, where's the practice-based evidence? Family Practice, 25(supp. 1), i20-i24. https://doi.org/10.1093/fampra/cmn055.

Greenhalgh, T., Robert, G., Macfarlane, F., Bate, P., \& Kyriakidou, O. (2004). Diffusion of innovations in service organizations: Systematic review and recommendations. Milbank Quarterly, 82(4), 581-629. https://doi.org/10.1111/j.0887-378x.2004.00325.x.

Hoagwood, K. E., Olin, S. S., Horwitz, S., McKay, M., Cleek, A., Gleacher, A.,... Kuppinger, A. (2014). Scaling up evidence-based practices for children and families in New York State: Toward evidence-based policies on implementation for state mental health systems. Journal of Clinical Child \& Adolescent Psychology, 43(2), 145-157. https://doi.org/10.1080/15374416.2013.869749.

Horwitz, S. M., Hurlburt, M. S., Goldhaber-Fiebert, J. D., Palinkas, L. A., Rolls-Reutz, J., Zhang, J., ... Kuppinger, A. (2014). Exploration and adoption of evidence-based practice by U.S. child welfare agencies. Children and Youth Services Review, 39, 147-152. https ://doi.org/10.1016/j.childyouth.2013.10.004.

Kazdin, A. E., \& Weisz, J. R. (Eds.). (2003). Evidence-based psychotherapies for children and adolescents. New York: Guilford Press.

Kendall, P. C., Hudson, J. L., Gosch, E., Flannery-Schroeder, E., \& Suveg, C. (2008). Cognitive-behavioral therapy for anxiety disordered youth: A randomized clinical trial evaluating child and family modalities. Journal of Consulting and Clinical Psychology, 76(2), 282-297. https://doi.org/10.1037/0022-006x.76.2.282.

Knudsen, H. K., \& Roman, P. M. (2004). Modeling the use of innovations in private treatment organizations: The role of absorptive capacity. Journal of Substance Abuse Treatment, 26(1), 51-59. https://doi.org/10.1016/s0740-5472(03)00158-2.

Maynard, B. R. (2010). Social service organizations in the era of evidence-based practice: The learning organization as a guiding framework for bridging science to service. Journal of Social Work, 10(3), 301-316. https://doi.org/10.1177/146801730934252 0 .

Mendel, P., Meredith, L. S., Schoenbaum, M., Sherbourne, C. D., \& Wells, K. B. (2008). Interventions in organizational and community context: A framework for building evidence on dissemination and implementation in health services research. Administration and Policy in Mental Health and Mental Health Services Research, 35, 21-37. https://doi.org/10.1007/s10488-007-0144-9.

Moullin, J. C., Dickson, K. S., Stadnick, N. A., Rabin, B., \& Aarons, G. A. (2019). Systematic review of the exploration, preparation, implementation, sustainment (EPIS) framework. Implementation Science, 14, 1-16. https://doi.org/10.1186/s13012-018-0842-6.

Nadeem, E., Saldana, L., Chapman, J., \& Schaper, H. (2018). A mixed methods study of the stages of implementation for an evidencebased trauma intervention in schools. Behavior Therapy, 49(4), 509-524. https://doi.org/10.1016/j.beth.2017.12.004.

National Cancer Institute. (2018). Qualitative methods in implementation science. Retrieved from https://cancercontrol.cancer.gov/IS/ docs/NCI-DCCPS-ImplementationScience-WhitePaper.pdf.

Olin, S. C. S., Chor, K. H. B., Weaver, J., Duan, N., Kerker, B. D., Clark, L. J.,... Horwitz, S. M. (2015). Multilevel predictors of 
clinic adoption of state-supported trainings in children's services. Psychiatric Services, 66(5), 484-490. https://doi.org/10.1176/ appi.ps.201400206.

Padgett, D. K. (2012). Qualitative and mixed methods in public health. Thousand Oaks, CA: Sage.

Palinkas, L. A., Holloway, I. W., Rice, E., Fuentes, D., Wu, Q., \& Chamberlain, P. (2011). Social networks and implementation of evidence-based practices in public youth-serving systems: A mixed-methods study. Implementation Science, 6, 113-123. https ://doi.org/10.1186/1748-5908-6-113.

Palinkas, L. A., Horwitz, S. M., Green, C. A., Wisdom, J. P., Duan, N., \& Hoagwood, K. (2015a). Purposeful sampling for qualitative data collection in mixed method implementation research. Administration and Policy in Mental Health and Mental Health, 42, 533-544. https://doi.org/10.1007/s10488-013-0528-y.

Palinkas, L. A., Wu, Q., Fuentes, D., Finno-Velasquez, M., Holloway, I. W., Garcia, A., et al. (2015b). Innovation and the use of research evidence in youth-serving systems: A mixed-methods study. Child Welfare, 94(2), 57-85.

Palinkas, L. A., Saldana, L., Chou, C. P., \& Chamberlain, P. (2017). Use of research evidence and implementation of evidence-based practices in youth-serving systems. Children and Youth Services Review, 83, 242-247. https://doi.org/10.1016/j.childyouth .2017.11.005.

Panzano, P. C., \& Roth, D. (2006). The decision to adopt evidencebased and other innovative mental health practices: Risky business? Psychiatric Services, 57(8), 1153-1161. https://doi. org/10.1176/ps.2006.57.8.1153.

Powell, B. J., Patel, S. V., Haley, A. D., Haines, E. R., Knocke, K. E., Chandler, S., ... Aarons, G. A. (2019). Determinants of implementing evidence-based trauma-focused interventions for children and youth: A systematic review. Administration and Policy in Mental Health and Mental Health Services Research. Advance online publication. https://doi.org/10.1007/s10488-019-01003-3.

Proctor, E., Silmere, H., Raghavan, R., Hovmand, P., Aarons, G., Bunger, A., ... Hensley, M. (2011). Outcomes for implementation research: Conceptual distinctions, measurement challenges, and research agenda. Administration and Policy in Mental Health, 38(2), 65-76. https://doi.org/10.1007/s10488-010-0319-7.

Purtle, J., Lê-Scherban, F., Nelson, K. L., Shattuck, P. T., Proctor, E. K., \& Brownson, R. C. (2019). State mental health agency officials' preferences for and sources of behavioral health research. Psychological Services. Advance online publication. https://doi. org/10.1037/ser0000364

Rogers, E. M. (2003). Diffusion of innovations (Vol. 5). New York: Free Press.
Silverman, W. K., \& Hinshaw, S. P. (2008). The second special issue on evidence-based psychosocial treatments for children and adolescents: A 10-year update. Journal of Clinical Child \& Adolescent Psychology, 37, 1-7. https://doi.org/10.1080/153744107018177 25.

Sofronoff, K., \& Farbotko, M. (2002). The effectiveness of parent management training to increase self-efficacy in parents of children with Asperger syndrome. Autism, 6(3), 271-286. https://doi. org/10.1177/1362361302006003005.

Solomons, N. M., \& Spross, J. A. (2011). Evidence-based practice barriers and facilitators from a continuous quality improvement perspective: An integrative review. Journal of Nursing Management, 19, 109-120. https://doi.org/10.1111/j.1365-2834.2010.01144.x.

Strauss, A. L., \& Corbin, J. (1998). Basics of qualitative research (2nd vol). Thousand Oaks, CA: Sage.

Valente, T. W. (1996). Social network thresholds in the diffusion of innovations. Social Networks, 18(1), 69-89. https://doi. org/10.1016/0378-8733(95)00256-1.

Valente, T. W., Chou, C. P., \& Pentz, M. A. (2007). Community coalitions as a system: Effects of network change on adoption of evidence-based substance abuse prevention. American Journal of Public Health, 97(5), 880-886. https://doi.org/10.2105/ ajph.2005.063644.

Valente, T. W., \& Davis, R. L. (1999). Accelerating the diffusion of innovations using opinion leaders. The Annals of the American Academy of Political and Social Science, 566(1), 55-67. https:// doi.org/10.1177/0002716299566001005.

Viera, A. J., \& Garrett, J. M. (2005). Understanding interobserver agreement: The kappa statistic. Family Medicine, 37(5), 360-363.

Willms, D. G., Best, J. A., Taylor, D. W., Gilbert, J. R., Wilson, D., Lindsay, E. A., et al. (1990). A systematic approach for using qualitative methods in primary prevention research. Medical Anthropology Quarterly, 4(4), 391-409. https://doi.org/10.1525/ maq.1990.4.4.02a00020.

Wisdom, J. P., Chor, K. H. B., Hoagwood, K. E., \& Horwitz, S. M. (2014). Innovation adoption: A review of theories and constructs. Administration and Policy in Mental Health and Mental Health Services Research, 41(4), 480-502. https://doi.org/10.1007/s1048 8-013-0486-4.

Publisher's Note Springer Nature remains neutral with regard to jurisdictional claims in published maps and institutional affiliations. 